\title{
A "CLEMENTIA PRINCIPIS" DE NOSSOS DIAS, NO DIREITO NACIONAL
}

\author{
Otávio de Sá Barreto \\ Professor-Instrutor da Faculdade de Direito da \\ Universidade do Paraná.
}

Se há, no corpo de leis do país, instituto que, quanto à sua exata aplicação, ofereça insegurança de hermenêutica e que admita, assim, conceitualística dúbia e discrepante, será êle, por certo, entre nós, o instituto jurídico da graça.

Muito embora encontremos plasmado na Carta Magna o poder para a sua concessão, no Código Penal, a sua classificação na esfera do direito positivo, a regulamentação do modo de serem deferidos os seus benefícios, no de Processo Penal e, nos fartos estudos e lições da doutrina, todos os elementos informativos ao seu completo conhecimento, o mencionado instituto, nos quadros de sua aplicabilidade, continua vacilante e, por isso mesmo, sem as características tranquilizadoras da certeza e da firmeza, que devem ser o apanágio das criações da ciência do direito.

Curioso é assinalarem-se tais circunstâncias ,pois, além do do mais, em que pesem as variedades e até esdruxulas $\$$ formas pelas quais êle se concretiza na prática, não tem faltado singular complascência por parte de autores e da jurisprudência, procurando justificar-lhe e aceitando-lhe as incongruências.

Para o raciónínio e o entendimento, principalmente, dos estudantes de nossas Faculdades de Direito, a matéria, por isso mesmo, deve apresentar-se mais confusa ainda, gerando nos que dêsde cedo se inclinam para a pesquifa, tormentosos problemas de indecisão. 
Não queremos, contudo, agravar êsse estado de coisas, com um levantamento das inúmeras diferenciações que existem nas diversas formas da "Clementia Principis", mostrando a discordância desnorteante que há entre os textos, a doutrina e a prática, bastando que, "ad-exemplum" e em apơio de nossa despretenciosa observação, para aqui traslademos, a propósito, face à referida fragilidade de conceitualística, máxime na aludida prática, o autêntico desabafo de um mestre, o eminente professor Aloysio de Carvalho Filho, quando, em seus comentários ao n..$^{\circ}$ II, do artigo 108, de nosso Código Penal (Com. ao Cod. Penal Pg. 117, vol. IV - 3.a ed. Rio, 1955 - Ed. da "Revista Forểnse"), profliga: - "As clássicas distinções entre a anistia e a graça ou indulto, quais sejam, anistia, atribuição do Poder Legislativo, indulto, atribuição do Poder Executivo; anistia, para processados ou condenados, indulto, para condenados; anistia, para os crimes políticos e conexos; indulto, para os crimes comuns; anistia, favor coletivo indulto, favor individual, ainda que alcançando um grupo de condenados; anistia, medida iminentemente retroativa, envolvendo o crime em olvido completo; indulto, medida de efeitos sòmente para o futuro, deixando subsistir o crime; essas e outras distinções que tais, não oferecem, hoje, nem prática, nem teòricamente, a menor segurança ao estudioso, para delimitação do conceito e finalidade dos dois institutos, de orígem comum e tantas características semelhantes. E não oferecem segurança, porque têm existido indultos com efeito de anistia, anistias decretadas pelo Executivo, indulto a simples processados, anistia para crime comum, indulto para crime político, anistia individualizando delinqüëntes, indulto a uma generalidade de condenados não individualizados, e outras singularidades mais, que dificultam a diferenciação".

Nada mais significativo, mais concludente e de mais meridiana percepção.

Mistér nem se faz, daí, que, bosquejando as raizes do instituto da graça, nos gastemos em escorço histórico, para aprecia-lo no seu estado atual e mostrarmos que, mesmo antes da vigencia da Constituição de 46, já aquêles laivos de dubiedade, assen- 
tes na variedade da aplicação prática dos benefícios em causa, conturbavam a preocupação dos mestres e comentaristas, uma vez que, com o advento do diploma máximo por que ora regemos, à falta, afigura-se-nos, principalmente, de atualização ou adatação da matéria nos Códigos Penal e de Processo Penal, o instituto mais ainda se extremou dos vícios de que sempre se ressentiu.

É de ver-se.

Para facilidade dêste nosso palido esbôço de comentário e visando a torná-lo o mais breve possível, desprezemos destás ligeiras apreciações a "Clementia Principis", no tocante à anistia, que é da competência do Legislativo, menos ligada ao interêsse da processualística criminal e, digamos, mais rara ou menos habitual nas lides do fôro, dêsde que respeita mais aos crimes políticos, e examinemo-la, tão só, quanto aos seus outros aspectos cuja concessão é do Executivo.

$\mathrm{E}$, nesse exame, busquemos, de preferência, as prováveis causas do tumulto que a vem agitando e que, hodiernamente, mais ainda a convulsiona.

Não remontemos a muito longe.

A Constituição Federal decretada em 1.937, na letra $f$, do seu artigo 75, como uma das prerrogativas do Presidente da República, consignava-lhe, "tout court", a de "exercer o direito da graça”.

Conferia-se, assim, ao Chefe da nação, a outorga total da faculdade privativa do exercício do soberano direito de graça, se bem que, em razão da sistemática do regime, que não era possível ou não convinha suprimir de todo, apefar do obscurantismo do domínio totalitário em que o Brasil se amortalhava, - fôssem, não obstante, mantidas as prerrogativas da anistia e da reabilitação, que também se incluem no instituto jurídico da graça (1), aquela, deferida, com exclusividade, ao Congresso nacional e esta, à órbita das atribuições do Judiciário.

(1) CASTRo NUNES, citando Brunialti: ("Teoria e Prat. do Poder Ju. diciário" pg. 52): 
A consignação, todavia, não passava, mesmo, de pura formalística, dềsde que, respeitada que foi, na lei máxima, a parte de exclusividade ao Legislativo, êste nunca foi convocado, no período do chamado Estado Novo, donde sua competência nunca deixou de ser absorvida e usurpada pelo Executivo, com os famosos "decretos-leis".

Era, aliás, como não podia deixar de ser, um dos índices marcantes da mentalidade da época a realçar, enaltecer e robustecer a figura ímpar do "chefe", ainda mais quando, na espécie, a matéria se filiava ao poder, de origem divina, reconhecido ao Príncipe.

Mas, retornemos à "magna pars" do assunto.

Conferida ao Presidente a prerrogativa de "exercer o direito de graça", é claro que, por extensão, nêsse mesmo direito, se comportava, também, além da graça ou perdão pròpriamente dito, o indulto que, sendo a igual, uma forma de clemência do poder público, autorizava o supremo magistrado, em concedendo-o, bem como com o que ocorria com a mencionada graça, extinguir, comutar ou diminuir penas.

Justo, por isso, quer nos parecer, para o contido na letra $f$, do artigo 75 daquela Constituição, embora o inciso não falasse, em indulto, sendo êste, como ressalta da doutrina, forma de clemência do poder público, justo, por isso, diziamos, foi que veio êle a incluir-se nos citados Códigos, como modalidade do direito de graça.

Com apoio, ainda, na doutrina, brilhante e exaustivamente exposta e sustentada pela quase totalidade dos autores patrícios, no que, aliás, se alicerçam nos mestres estrangeiros, para só versarmos, como é de nosso objetivo, sôbre o ângulo de instituto, no que tange aos privilégios assegurados ao primeiro mandatário da nação, se bem que graça ou indulto lhe possibilitem a concessão de três espécies ou formas de clemência: perdão integral da pena ou sua extinção, sua redução, ou sua conversão em pena mais branda, há que considerar-se - e êsse talvez seja o ponto capital de nossos desvalidos e perfuntórios apontamentos - que graça e indulto, apęar de serem iguais 
nos seus efeitos jurídicos, quanto à sua conceituação de direito se diferenciam, profundamente, possuindo, cada qual, características especiais.

Investiguemos, a "vol d'oiseau", no que consiste tal diferenciação.

De modo geral e por assim dizer, pacífico, entendem os doutrinadores, em resumo, que a graça ou perdão pròpriamente dito, é individual, ou melhor ,é a clemência do poder público (Presidente), favorecendo a um criminoso ou sentenciado, especificamente, sob os três aspectos de extinção da pena, sua redução, ou sua comutação, e, o indulto, é idêntica clemência, mas de caráter geral, e coletivo e, a igual, sob os três mesmos aspectos, a um grupo, porém, de delinqüêntes ou condenados, simultâneamente.

A simples enumeração dessa diferença implica, como ainda c. faz ver a doutrina, no entendimento claro, lógico, jurídico e até intuitivo, de que a graça, para sua obtenção, deve ser requerida ou solicitada, ao passo que, o indulto, será ato espontâneo do seu outorgante, não admitindo, daí, petitório.

Raimundo Macedo, na sua esplêndida monografia "Da Extinção da Punibilidade" (Ed. da "Revista Forênse" - Rio, 1946), em várias passagens diz que, "apeq́ar de nossas leis nunca terem distinguido o indulto da graça, aquêle e esta são coisas distintas, por ser, a graça, exercida em favor de uma determinada pessoa e, o indulto, concedido a todos os que indistintamente, incorreram em determinada pena".

Geminiano da Franca (2) ensina que a graça ou perdão é individual e que, coletivo é o indulto abrangendo como abrange, uma categoria de crimes ou de penas, pelo que aproveita a todos os condenados que se acharem nas condições a que se refira o ato de clemência do poder público, que é ato espontâneo dêste e que não tem por objetivo corrigir o êrro judiciário,

(2) Geminiano da Franca (O Instituto Jurídico da Graça, in - "Arquivo Judiciário" - Suplemento dos vls. 27 a 29,1933 pgs. 30 e 200). 
nem recompensar o arrepenaimento, mas sim, o interesse público, as vantagens que decorrem, para a sociedade, da suspensão das penas aplicadas a determinadas infrações penais".

Vê-se por aí, que a diferericiação existe, que, graça, é uma coisa e, outra, o indulto; que êste é ou devia ser sempre de ca$r^{r i}$ er coletivo e impessoal, ao passo que a outra, individual e pessoal; que graça sempre pressupõe a existência de sentença, em grau irrecorrível e que indulto pode até preceder sentença condenatória, embora, em comum, tenham os efeitos de reduzir, no todo ou em parte, ou substituir as penas impostas; que, além do mais, se a diferenciação não existisse, afinal não deixaria de ser uma incorreção técnica, inadmissível nos textos jurídicos, o uso de sinonímia para as mesmas formas do instituto.

Tudo, não obstante, poderia estar certo, até então, eis, que, legislando sôbre a aplicação do instituto, para prescrever-lhe as finalidades e regular-lhe os modos e formas de utilização juđiciária, dêle se ocuparam, como ainda se ocupam e como näo poderia deixar de acontecer, tanto o Código Penal, como o do respectivo Processo, sob a égide constitucional contemporânea.

E, assim, o primeiro cataloga-o no n. ${ }^{\circ} \mathrm{II}$, do seu artigo 108, como das causas determinantes da extinção da punibilidade, apresentando-o sob o duplo aspecto da anistia e da graça ou indulto e, o outro, traçando-lhe a processualística, do artigo 734 ao 742, a êle se refere, já, agora, sob a tríplice modalidade de graça de indulto e de anistia.

Era de admitir-se, contudo, tal mistura, pois elaborados e postos em vigor ao influxo daquela Constituição e não podendo a lei ordinária limitar o que a lei máxima consagra de modo amplo, se a Carta Magna de então conferia ao Presidente da República, como prerrogativa exclusiva, exercer, sem restrições, o direito de graça, estavam os Códigos sujeitos a tratar dêsse mesmo direito, sob tôdas as suas modalidades, para destarte, cumprir-se, em tôda plenitude, o preceito do diploma máximo. 
Já em nossos dias, o problema surge sob prisma diferente e vestindo roupagem diversa.

É que, pela Constituição promulgada em 1.946, compete, privativamente, ao Presidente da República, segundo se lê, no n. ${ }^{\circ}$ XIX, do seu artigo 87, apenas:

- "Conceder indulto e comutar penas, com audiência dos órgãos instituidos em lei".

Não mais se nos depara, aí, no texto imperativo da Lei das Leis, a prerrogativa anterior do exercício amplíssimo, ao supremo magistrado, do direito de graça que, não fôsse o pudor ou a conveniência de aparentar o regime democrático, abrangeria, na própria Constituição, naquêles idos tenebrosos, inclusive a anistia e a reabilitação.

A "Clementia Principis" outorgada ao Presidente, por força constitucional, cinge-se ao indulto e à comutação de penas, esta, que outra coisa não é senão o próprio indulto, quando aplicado para substituir penas, nada existindo mais em relação à graça, ou à graça individual ou perdão, pròpriamente dito.

Os dispositivos dos Códigos, não obstante, dềsde que não foram modificados, nem adotados, permaneceram, como dantes, já agora, em choque com a Constituição, por isso que o Penal ainda estipula como causas extintas da punibilidade: 1) a anistia e, 2) a graça ou indulto e o de Processo ainda se refere: 1) à graça, 2) ao indulto e 3) à anistia.

Como entender-se tal estado de coisas?

A Constituição silencia sôbre a graça ou perdão individual, - Código Penal não só a consigna, como equipara-a ao indulto e, o de Processo, além de igualmente consigna-la, a distingüe, todavia, do indulto.

$\hat{E}$ de estontear.

Difícil se torna, portanto, firmar-se juízo a respeito, para melhores e mais explícitas discriminações sôbre as particularidades da "Clementia Principis" de nossos dias, não se logrando, assim, colher clara, metódica e correta a conceituação que se deve fazer do instituto jurídico da graça entre nós, já tão 
confuso e malvertido na sua aplicabilidade prática, conforme vimos observando.

Atentas as diferenciações que os autores discriminam entre graça e indulto e as de que acima já nos ocupamos, como conciliar os textos codificados com as atuais prescrições constitucionais?

E, o pior, é que, sendo outra a Carta Magna do Brasil de hoje, parece que se ignora tal realidade e, para a espécie, ainda se continua a agir dentro da processualística anterior, como se nada de novo tivesse acontecido ,como se "outro valor mais alto não se tivesse alevantado".

Afigura-se-nos, portanto, que a conjuntura é relevante, que \& matéria merece maior atenção e que os estudiosos e os mestres deviam volver, com mais carinho, suas vistas para o assunto, afim de que, bem, pesquizado o problema, se traçasse diretriz firme e acertada para a sua radical solução, tornando-se assim estreme de dúvidas, vacilações hermenêuticas e inseguranças de aplicação, entre nós, êsse tão belo, quanto nobre, útil e humanitário Instituto Jurídico da Graça. De acồrdo,

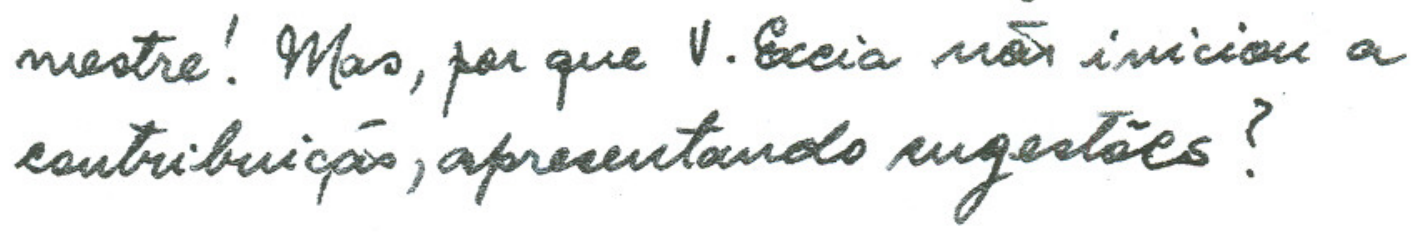

